\title{
An investment in knowledge....producing new interest
}

An investment in knowledge always pays the best interest.

Benjamin Franklin

When the Department of Education - now the Department of Higher Education and Training (DHET) - replaced the 'SAPSE-110' higher education funding system with the 'New Funding Formula' (NFF) in 2004, it is unlikely that they imagined it would give rise to an entire new industry within university administrations: the management of journal and book publication outputs by academic committees and by research support departments. Yet this is exactly what happened. What also happened was a dramatic rise in research publications and the graduation of students with master's and PhD degrees. Charles Sheppard ${ }^{1}$ of the Nelson Mandela Metropolitan University gathered data from the DHET's HEMIS (Higher Education Management Information System) and provided the overview of research outputs shown in Figure 1.

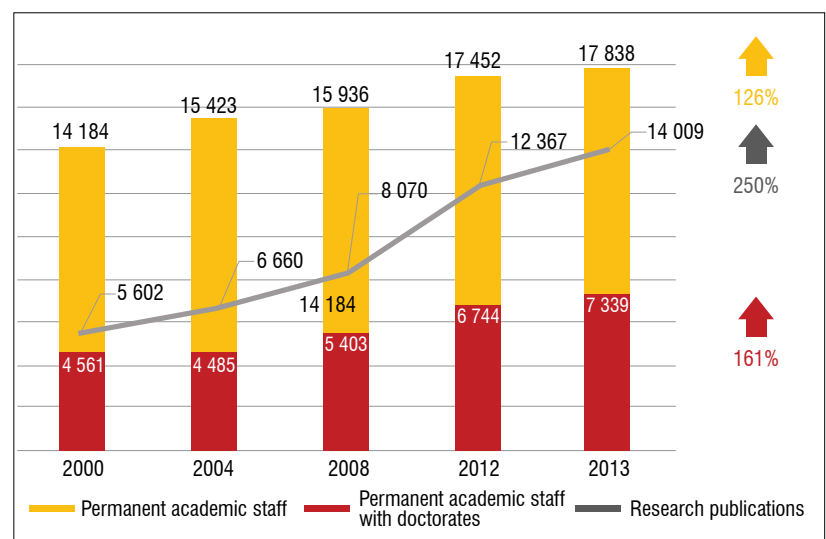

Source: Sheppard ${ }^{1}$

Figure 1: Research output of South African universities.

In brief, publication outputs increased by $18.9 \%$ between 2000 and 2004 , by $30.7 \%$ between 2004 and 2008 after the NFF had been introduced, and then by a further $53.2 \%$ in the years between 2008 and 2012 - an increase of $250 \%$ over the entire period covered by Sheppard's data. And while the number of academic staff increased by $126 \%$ over the review period, the number of academic staff members with doctorates increased by $161 \%$.

Comparative data for the periods prior to 2000 are not easily found, but Bawa and Mouton ${ }^{2}$ published the publication outputs for the years 1990 to 1998 (Figure 2).

Bawa and Mouton ${ }^{2}$ advance several hypotheses, drawn from different sources, to explain the fall of productivity between 1991 and 1992, and again between 1995 and 1998 - but the implication to be drawn from the data provided by Sheppard ${ }^{1}$ is that the decline continued through to 2000 , then initially rose slowly but gathered considerable momentum after the introduction of the NFF.

Apparent correlations between calendar dates, education policies and research productivity do not prove inevitable causality - but it would be hasty to ignore possible coincidence in the absence of other possible explanations. At the very least, the data would seem to imply that investment in knowledge production can prove to be a positive incentive.
Over the years since 2004, the rules, requirements and processes on which the award of research output funds has been based have changed, and the role of agencies has changed, with the Academy of Science of South Africa (ASSAf) taking on the major assessment and recommendation activities of 2014 and 2015.

In March this year, more substantial changes were announced, which will take effect from the 2016 round of assessments and grants. Details of the changes have been summarised by most universities, but the broad picture that emerges from the March policy is a thoughtprovoking reflection on current conditions in the world of academic cooperation and publishing.

The section that deals with journals, for instance, reminds universities to be aware of predatory journals, with, it would seem, the intention of alerting researchers to these scams whilst also ensuring that papers in these journals are not listed for awards. More stringent conditions are also specified for the recognition of accreditation of journals: local journals are encouraged, through their Editors-in-Chief, to apply for local accreditation even if they are not Web of Science or Scopus listed - and to ensure that they meet the DHET accreditation requirements.

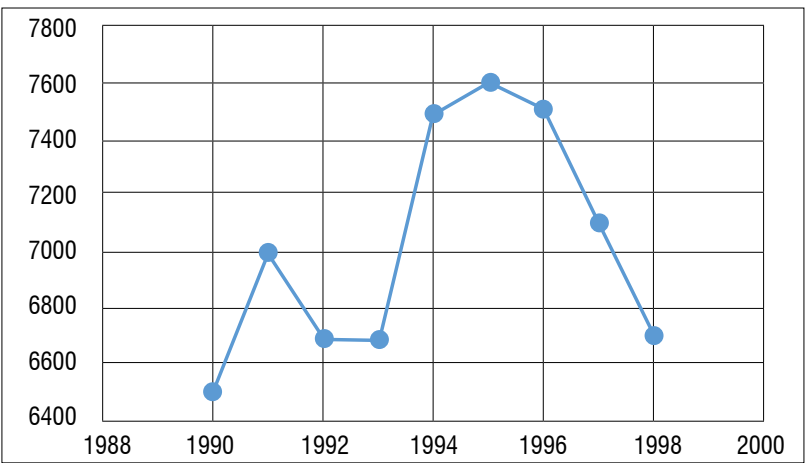

Source: Bawa and Mouton

Figure 2: Scientific output of South African universities from 1990 to 1998.

Conference proceedings, keynote addresses, works in progress, short papers, brief communications and technical notes may now also be considered for awards, provided that the conference is approved by the DHET. In addition, more than $60 \%$ of contributions published in conference proceedings must emanate from multiple institutions.

The new conditions for awards for books are, perhaps, the most onerous and, at the same time, the most generous. The maximum subsidy for a book is now 10 units, although the award will depend on the length of the book: at the lower end, a book length of 60-90 pages will generate 2 units, while at the upper end (300 or more pages), a book will earn the maximum 10 units. A chapter in a book will qualify for two units. Books (and their chapters) will, however, require a written justification (of no more than 500 words) signed by the author of the book, or the general editor, explaining the contribution that the book makes to scholarship. This justification may not be an abstract of the contents or preface of the book, but must, rather, describe the methodology used as well as the unique contribution made to knowledge production. The justification will also need to clarify that the book or chapter for which subsidy is claimed disseminates original research and new developments within the specific discipline. 
The justification must also include an unambiguous declaration that no part of the work was plagiarised or published elsewhere, and specify the target audience. A statement from the institution's evaluation committee is also required, indicating that it has thoroughly checked both the previous and current editions and affirming that at least $50 \%$ of the work has not been published previously, and that the book has been peer reviewed both before and after publication.

For scholars, there remain two cautionary notes. University screening committees are tasked with screening submissions, but they are not obliged to accept those submissions, even if they appear to meet all of the DHET requirements - and the ASSAf/DHET teams are not bound to agree with the institutional committees. Most critically, the pool of publication award funds does not increase each year. So as long as the pie's circumference remains more or less constant, the award slices will diminish in relation to the increase in the number of successful submissions. Today's unit value of ZAR113 000 will, inevitably, become tomorrow's ZAR90 000 or less.

\section{References}

1. Sheppard C. Research output of South African universities [HEMIS database]. Cape Town: Centre for Higher Education Transformation; 2013.

2. Bawa AC, Mouton J. Research. In: Cloete N, Maassen P, Fehnel R, Moja T, Gibbon T, Perold H, editors. Transformation in higher education: Global pressures and local realities in South Africa. 2nd ed. Dordrecht: Springer; 2006. p. 195-225. http://dx.doi.org/10.1007/1-4020-4006-7_15 